\title{
REVIEW ARTICLE
}

\section{High Performance Polybenzoxazines as a Novel Type of Phenolic Resin}

Polybenzoxazines that can be obtained by the thermally induced ring-opening polymerization of cyclic benzoxazine monomers are expected as a novel type of phenolic resins. Herein, we report on our various approaches for performance enhancement of polybenzoxazines, including the designs of novel monomers, high molecular weight polymeric precursors, polymer alloys, and hybrids with inorganics.

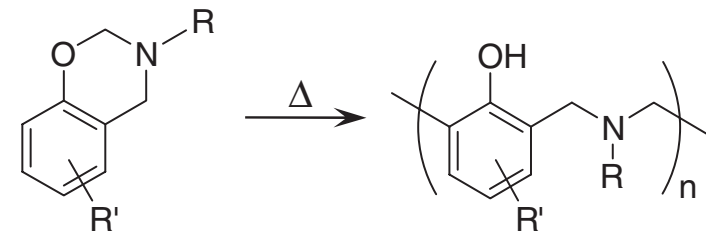

\section{High Performance Polybenzoxazines}

T. TAKEICHI, T. KAWAUCHI, and T. AGAG

Vol. 40, No. 12, pp 1121-1131 (2008)

\section{REGULAR ARTICLE}

\section{Self-organization of Water Soluble and Amphiphile Crosslinked Carboxymethylpullulan}

Hydrosoluble and amphiphile crosslinked derivatives of carboxymethylpullulan possess a double organization (chemical and physical) which evolve with polymer concentration and the nature of the solvent giving species with varied structure and size.

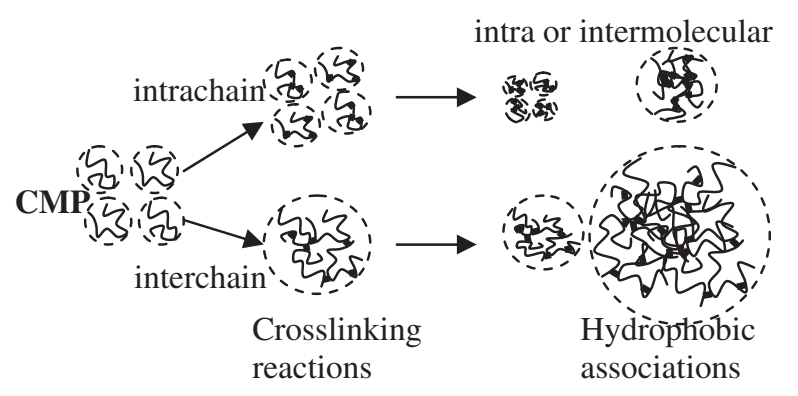

M. Legros, V. DuLong,

L. Picton, and D. Le Cerf

Vol. 40, No. 12, pp 1132-1139 (2008)
Homopolymerization and Copolymerization with Styrene of Various Alkoxyvinylsilanes and Oxidative Transformation of C-Si Bond in the Resulting Copolymers to Afford Poly[(vinyl alcohol)-co-styrene]s

Radical (co)polymerization behavior of various alkoxyvinylsilanes 1-6 was systematically investigated. Homopolymerization and copolymerization with styrene of these alkoxyvinylsilanes were performed under various conditions in order to find appropriate initiating systems for the radical polymerizations. Transformation of some of the copolymers into poly(vinyl alcohol-co-styrene)s was examined via oxidative cleavage of the $\mathrm{Si}-\mathrm{C}$ bonds in the alkoxyvinylsilane repeating units. 
Synthesis and Properties of Segmented Poly(urethaneurea)s Containing Phosphorylcholine Moiety in the Side-Chain

Novel segmented poly(urethane-urea)s containing phosphorylcholine (PC) group were prepared from the aromatic diamine compound with PC group. The obtained poly(urethane-urea)s exhibited the elastic property derived from the main chain structure, and also the excellent biocompatibility even though the PC content was around $15 \mathrm{wt} . \%$. Therefore, the introduction of PC group in the side chain of polymers was effective to develop the biocompatibility, which would be due to the surface property covered with polar PC units.

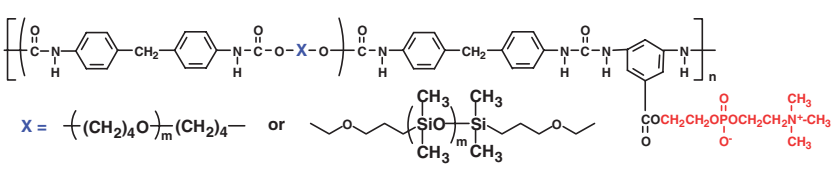

Y. NAGASE, S. NAKAJIMA, M. OKU, Y. IWASAKI, and K. ISHIHARA

Vol. 40, No. 12, pp 1149-1156 (2008)
Preparation and Characterization of Poly(vinylpyrrolidone)/Zirconium Oxide Hybrids by Using Inorganic Nanocrystals

PVP and $\mathrm{ZrO}_{2}$ nanocrystal hybrids were prepared by simple blending method. Hydrogen bonding interactions between amide groups of PVP and $\mathrm{Zr}-\mathrm{OH}$ groups from $\mathrm{ZrO}_{2}$ nanocrystal played an important role for the homogeneity and transparency of PVP/ $\mathrm{ZrO}_{2}$ hybrids. The $\mathrm{ZrO}_{2}$ nanocrystals were dispersed well in the PVP matrix and demonstrated no aggregation and phase separation. The obtained hybrids exhibited excellent thermal and optical properties.

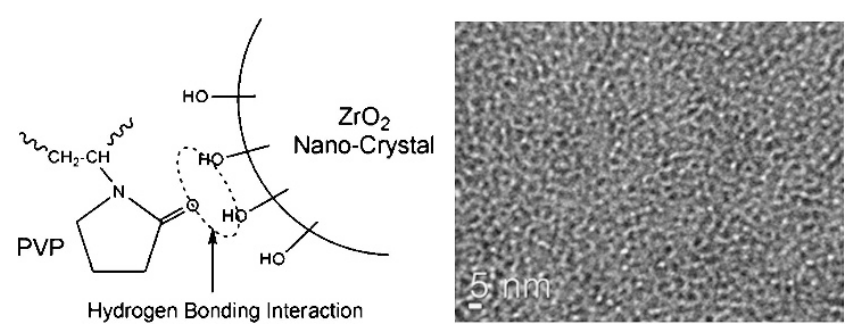

T. OTSUKA and Y. CHUJO

Vol. 40, No. 12, pp 1157-1163 (2008)

\section{Brand-new Biomass-based Vinyl Polymers from 5-Hydroxymethylfurfural}

Novel biomass-based vinyl polymers were synthesized from 5-(hydroxymethyl)furfural (HMF) or 5-(methoxymethyl)furfural (MMF) as the starting material. Poly(5-methoxymethyl-2-vinylfuran) (PMMVF) exhibited better thermal resistance than poly(5hydroxymethyl-2-vinylfuran) (PHMVF).

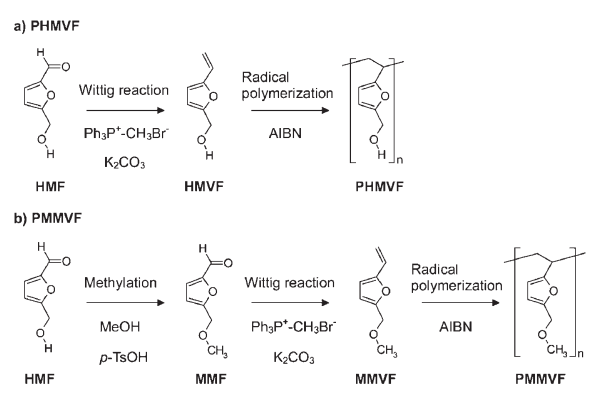

N. YOSHIDA, N. KasUYA,

N. HAGA, and K. FUKUDA

Vol. 40, No. 12, pp 1164-1169 (2008) 


\section{Modification of Cellulose by Using Atom Transfer Radical Polymerization and Ring-Opening Polymeriza- tion}

The cellulose chloroacetate (Cell-ClAc) with a degree of substitution (DS) value of about 2.1 was synthesized. And it was used as macro-initiator for ATRP of vinyl monomers. The preparation of block copolymers by using the first ATRP product as initiator for the second ATRP of another monomer was performed. In addition, the different reactions including AGET ATRP of 3-ethyl-3-methacryloyloxymethyloxetane (EMO) and ROP of cyclic ester proceed simultaneously in the same reaction system by using the same initiator was also carried out.

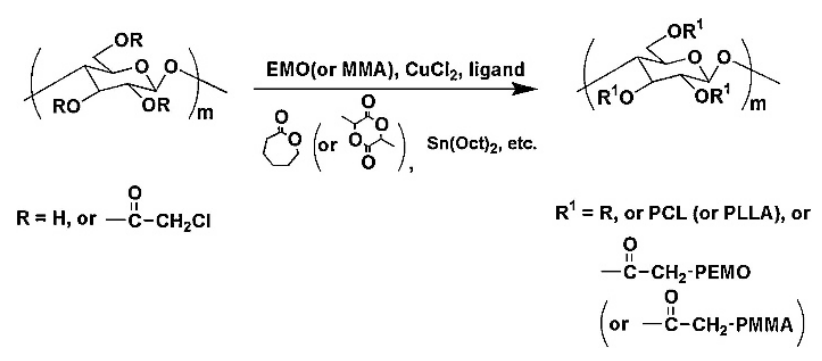

F. CHANG, K. YAMABUKI,

K. ONIMURA, and T. OISHI

Vol. 40, No. 12, pp 1170-1179 (2008)

\section{Honeycomb-Structured Porous Films Controlled by the Temperature of Water Bath}

A new technique based on Breath Figures method was introduced to fabricate porous film in a chamber with a water bath. The pore size of the film increases with an increase in the water-bath temperature. And the porous film from the "dilute" solution can be readily formed even at a low relative humidity $(\mathrm{RH})$, while the porous film from the "concentrated" solution can be fabricated only at a rather high $\mathrm{RH}$. The regularity of porous film becomes better at the higher $\mathrm{RH}$ and higher concentration.

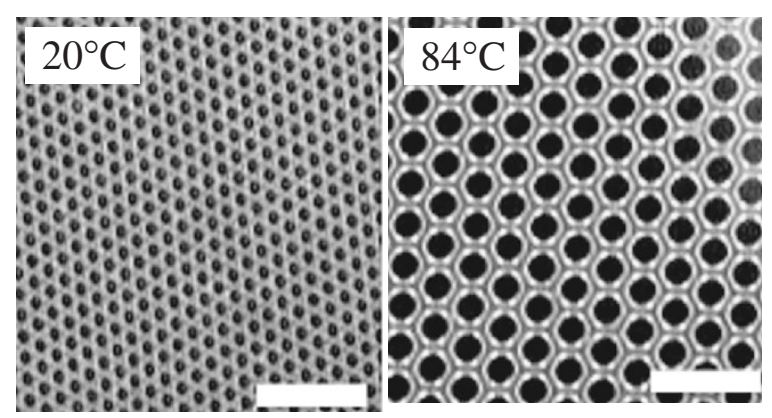

B. HE, J. LI, X. ZHANG, Z. LI, Y. Hou, and C. SHI

Vol. 40, No. 12, pp 1180-1184 (2008)

\section{Electronic Structure of Metallocene-based Polymers}

The band structures of metallocene-based polymers in which the nearest metalloecenes were directly linked by a $\mathrm{C}-\mathrm{C}$ bond have been determined by employing the tight-binding crystal orbital (CO) method. In particular, we determined the band structures of metallocene-based alternate copolymers whose metal sequences in a unit cell were $\mathrm{Fe}-\mathrm{Co}, \mathrm{Fe}-\mathrm{Fe}-\mathrm{Co}-\mathrm{Co}, \mathrm{Fe}-\mathrm{Ni}, \mathrm{Ru}-\mathrm{Co}$ and Os-Co. Furthermore, we examined the effect of inserting the bridging part of boron-, phosphorus-, and sulfur bridges between the nearest ferrocenes upon the band structures of ferrocene-based polymers.

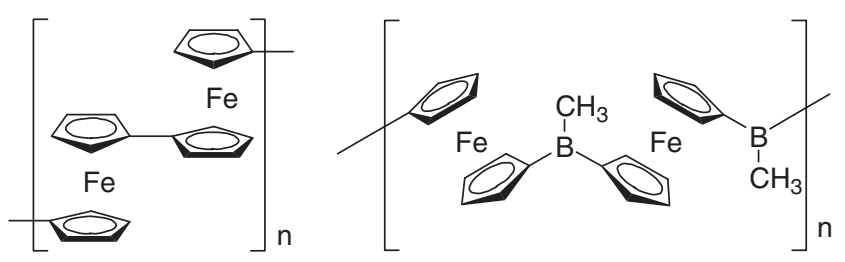

Y. MATSUURA, R. ODANI, and Y. TANAKA

Vol. 40, No. 12, pp 1185-1190 (2008) 
Two-dimensional Self-assembly of a Designed Amphiphilic Peptide at Air/Water Interface

A peptide having alternate sequence of hydrophobic and hydrophilic amino acid residues, (QAQL) ${ }_{4}$, and the corresponding PEG attached moiety, (QAQL) $)_{4}$-PEG were designed to form a nanoarchitecture on the basis of $\beta$-sheet structure at the air/water interface. The monolayer of (QAQL $)_{4}$ showed an arranged nanofibrous object. (QAQL) ${ }_{4}$-PEG showed a morphological change of the nano-architecture from disk-like structure to fibrous array depending on the compressing degree.
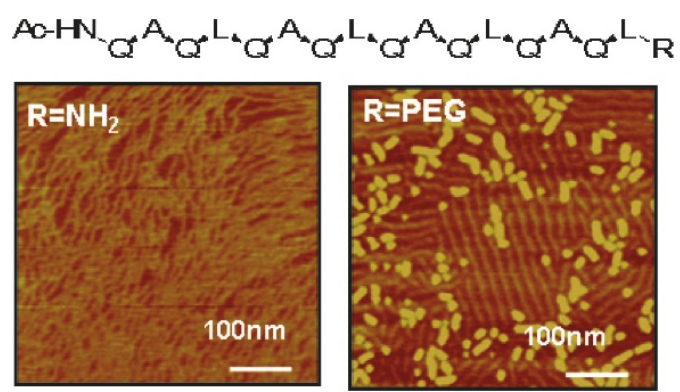

M. TANAKA, K. OGURA, S. ABIKO, N. KOSHIKAWA, and T. KINOSHITA Vol. 40, No. 12, pp 1191-1194 (2008)

\section{NOTE}

\section{Morphology and Structure of Ring-banded Spherulites Obtained by Solvent Evaporation in PLLA/PAAC Blend Films}

The crystallization behavior in thin films of poly(L-lactic acid) and an electroactive polyamide blends has been investigated by DSC, PLM and AFM. The concentric ring-banded spherulites were observed from DMF solution under a solvent evaporation rate of $2.8 \mu \mathrm{L} / \mathrm{min}$. In addition, the crystallization mechanism was also discussed.
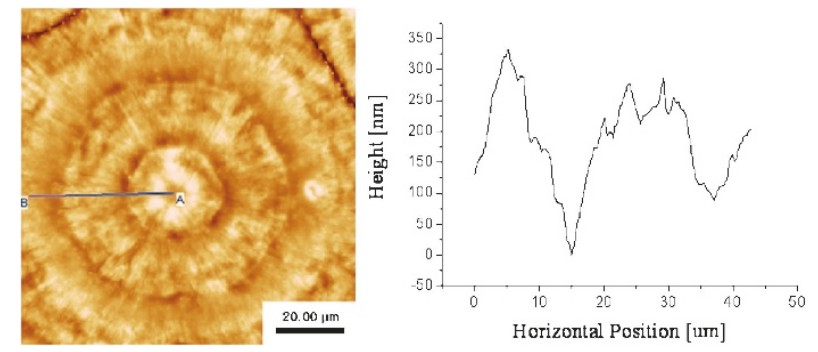

Y. LI, X. LIU, D. CHAO, L. CUI, and W. ZHANG

Vol. 40, No. 12, pp 1195-1198 (2008)

\section{Highly Conductive Polyfuran-13X Zeolite-Polyaniline Composite}

A composite of polyfuran with $13 \mathrm{X}$-zeolite was prepared for the first time using chemical oxidative polymerization of furan. The composite showed much improved thermal stability compared to bare polymer and behaved like an insulator. Interestingly incorporation of a small amount of conducing polyaniline significantly enhanced the conductivity. Entropy activation was proposed to explain such unexpected behavior regarding high conductivity of the binary polymer composite.
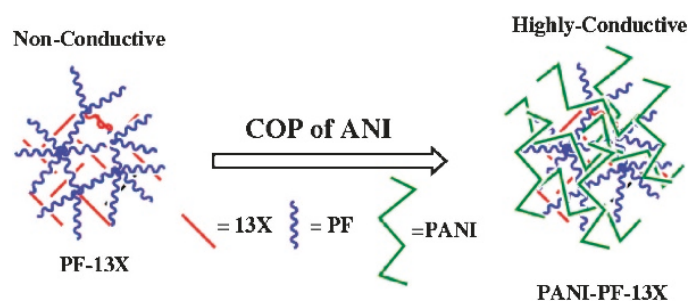

P. SAHA SARDAR, S. GHOSH,

M. BISWAS, and N. BALLAV

Vol. 40, No. 12, pp 1199-1203 (2008) 